\title{
Abrupt Climate Regime Shifts, Their Potential Forcing and Fisheries Impacts
}

\author{
Alfred M. Powell Jr. ${ }^{1}$, Jianjun $\mathrm{Xu}^{2 *}$ \\ ${ }^{1}$ NOAA/NESDIS/Center for Satellite Applications and Research (STAR), Camp Springs, Maryland \\ ${ }^{2}$ IMSG at NOAA/NESDIS/Star, Camp Springs, Maryland \\ E-mail: Jianjun.xu@noaa.gov
}

Received February 9, 2011; revised March 14, 2011; accepted March 21, 2011

\begin{abstract}
The purpose of this paper is to investigate whether a logical chain of events can be established to explain the abrupt climatic regime shift changes in the Pacific that link the atmosphere to the ocean to fisheries impacts. The investigation endeavors to identify synchronous abrupt changes in a series of data sets to establish the feasibility of abrupt of climate change often referred to as regime shifts. The study begins by using biological (fish catch/stock) markers to mathematically identify the dates of abrupt change. The dates are confirmed by a literature search of parameters that also show abrupt changes on the same dates. Using the biological date markers of abrupt change, analyses are performed to demonstrate that the interactions between the atmosphere, ocean, ecosystems and fisheries are a plausible approach to explaining abrupt climate change and its impacts.
\end{abstract}

Keywords: Climate Regime Shift, Fishery

\section{Introduction}

A number of fish stock studies have identified the apparent synchronous nature of many of the world's largest fish stocks (Food and Agriculture Organization (FAO), United Nations Fisheries Circular No. 920). These studies include the rise and fall of sardines in widely separated areas of the Pacific [1], as well as the out-of-phase nature of sardines and anchovies in multiple locations globally [2-5]. Based on the sardine/anchovy analysis, Chavez et al. [2] pointed out the abrupt changes in fish populations are difficult to explain on the basis of fishing pressure. Lehodey et al. [6] stated that fish population variability is closely related to environmental variability. In addition, he also points out that the low frequency population variability was first observed in small pelagic fish like sardines and anchovies but similar variability has been shown in larger fish like salmon, groundfish and tuna which track well with large scale climate patterns like the Pacific Decadal Oscillation (PDO) and the North Atlantic Oscillation (NAO). Chavez et al. [2] further remarked that the mechanism(s) responsible for the abrupt regime shifts should be relatively direct and simple, similar in the different regions, and likely linked with large-scale atmospheric and oceanic forcing.
The purpose of this research is to search for the large-scale forcing by identifying specific changes in the atmosphere, ocean and ecosystems that could offer a physical explanation for the chain of environmental interactions that could cascade through the system and affect the fisheries. The data and methodology are described in the next section and is followed by how the regime shifts were identified. Prior to the detailed analysis synopsis, background information on the global atmospheric wave pattern is provided for the multidisciplinary audience of readers. The analysis uses both a mathematical approach combined with a literature search to define the likely years of regime shifts. Based on the regime shift period identification, a top-down analysis (from atmosphere to ocean to fish) is performed to demonstrate regime shifts in the atmosphere can lead to wind stress changes. The wind stress impacts on ocean temperatures are shown with the consequential changes in fisheries impacts identified.

\section{Data and Methodology}

\subsection{Data}

The data used in this study include California's fishery 
landing data published by the California Department of Fish and Game (CDFG), reanalysis data sets created by the National Centers for Environmental Prediction (NCEP), the National Center for Atmospheric Research (NCAR) and sea surface temperature data produced by the National Climatic Data Center (NCDC) of the National Oceanic and Atmospheric Administration (NOAA).

1) California's fish landing data

The landings of California's fishery catch brought to shore are recorded by fish buyers, markets, and canneries and compiled by CDFG [7]. The annual commercial landings of fish and invertebrates are taken from the Southwest Fisheries Science Center located in the Pacific Fisheries Environmental Laboratory of NOAA. To track the variability of species from California's borders, this data set includes only the landings recorded as caught off California. The data spans the years 1928 to 2008. While the initial year for the raw data set was 1928, the initial record for each species starts from different times. The data includes the total catch for 31 marine species. The thirty one species are listed in Table 1.

\section{2) NCEP-NCAR reanalysis}

The monthly NCEP-NCAR reanalysis [8] with a $2.5^{\circ}$ $\times 2.5^{\circ}$ grid resolution is used for the periods of 1948 2008. It should be noted that the reanalysis period of 1948-1978 has no satellite data. The Television Infrared Observation Satellite (TIROS) Operational Vertical Sounder (TOVS) data, the Microwave Sounding Unit (MSU), the High Resolution Infrared Radiation Sounder (HIRS) and the Stratospheric Sounding Unit (SSU) information were not available before the end of 1978. The Special Sensor Microwave/Imager (SSM/I) data was assimilated in this system from 1993. The geopotential height and wind fields are used in the study.

Table 1. List of the 32 category names for California fish landings 1.

\begin{tabular}{cccc}
\hline Name & Code number & Name & Code number \\
\hline all & 1 & sanddab & 17 \\
barracuda & 2 & sardine & 18 \\
bass-giant & 3 & scorpionfish & 19 \\
bonito & 4 & shark & 20 \\
cabezon & 5 & sheephead & 21 \\
croaker-white & 6 & skate & 22 \\
flounder & 7 & smelt & 23 \\
halibut & 8 & sole & 24 \\
herring & 9 & swordfish & 25 \\
lingcod & 10 & tuna-albacore & 26 \\
mackerel-Jack & 11 & tuna-bluefin & 27 \\
mackerel-chub & 12 & tuna-skipjack & 28 \\
perch & 13 & turbot & 29 \\
rockfish & 14 & whitefish & 30 \\
sablefish & 15 & whiting & 31 \\
salmon & 16 & yellowtail & 32 \\
\hline
\end{tabular}

3) NCDC Extended Reconstructed Sea Surface Temperatures

The latest version of the Extended Reconstructed Sea Surface Temperatures (ERSST.v3) is used in this study, which is generated using in-situ SST data and improved statistical methods that allow stable reconstruction using sparse data. The monthly analysis extends from January 1854 to the present, but because of sparse data in the early years, the analyzed signal is damped before 1880 . After 1880, the strength of the signal is more consistent over time. ERSST is suitable for long-term global and basin wide studies; local and short-term variations have been smoothed in ERSST.

4) International Comprehensive Ocean-Atmosphere Data Set (ICOADS)

The International Comprehensive Ocean-Atmosphere Data Set (ICOADS) offers surface marine data spanning the past three centuries, and simple gridded monthly summary products for $2^{\circ}$ latitude $\times 2^{\circ}$ longitude boxes back to 1800 (and $1^{\circ} \times 1^{\circ}$ boxes since 1960). As it contains observations from many different observing systems encompassing the evolution of measurement technology over hundreds of years, ICOADS is probably the most complete and heterogeneous collection of surface marine data in existence.

\subsection{Methodology}

The geopotential height fields from the NCEP-NCAR reanalysis were decomposed into Fourier harmonics and the Fourier coefficients were used to recompose the temporal field for single zonal waves. Wavenumbers 1-6 are Fourier decomposed from the 61-yr (1948-2008) data. The wave height pattern anomaly is created by subtracting the mean heights for each wave from the original height average. Finally, using the fish landing analysis, the northern hemispheric wave pattern was analyzed to determine whether the typical cause-effect mechanism (atmospheric forcing, ocean change and fishery changes) could explain any potential linkages between the data sets and the regime shift dates.

\section{Northern Hemispheric Wave Pattern Background}

Meteorologists monitor the wave pattern by tracking the high and low pressure systems which are associated with fair and inclement weather respectively. The northern hemispheric wave pattern is used by forecasters to help predict future changes several days ahead. On a constant pressure surface, contouring the height of the pressure surface indicates the regions of counterclockwise winds (low pressure systems) and clockwise winds (high pressure systems). The winds blow parallel to the height contours above the boundary layer. Figure 1 shows two 


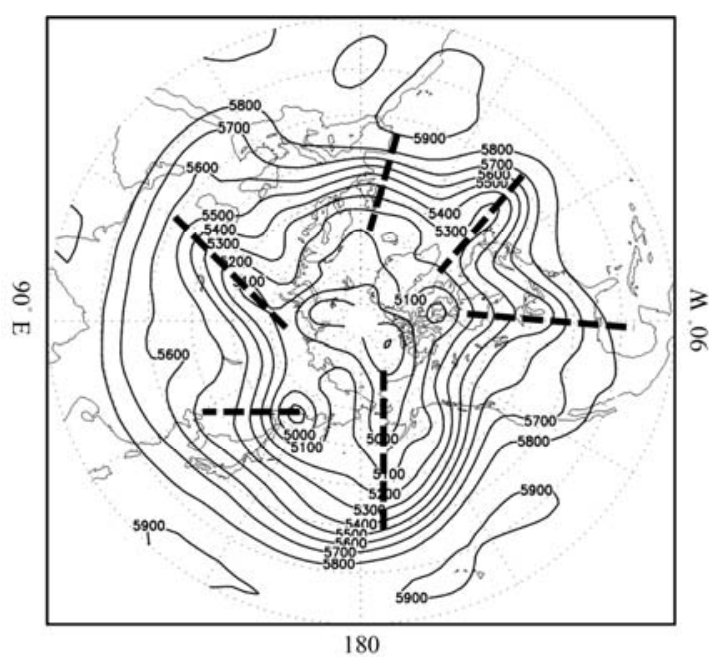

(a)

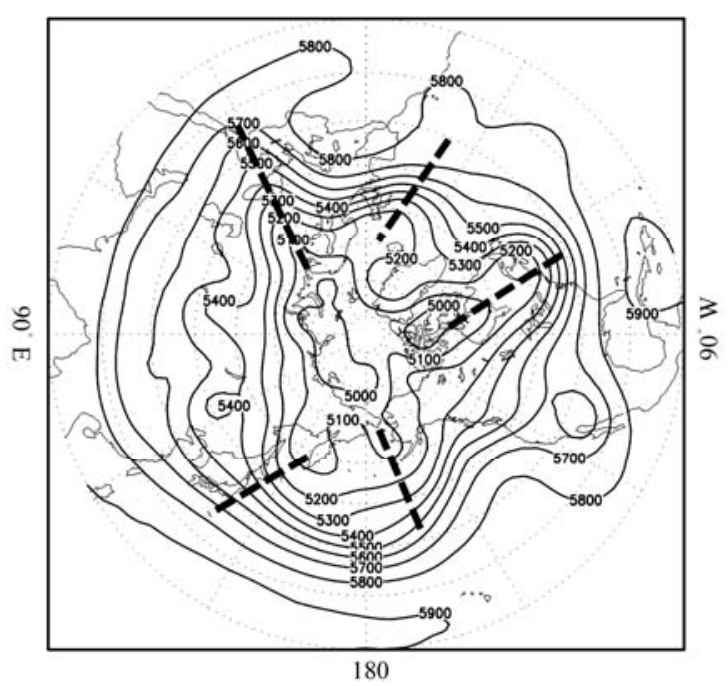

(b)

Figure 1. Pattern of geopotential height (gpm) at $500 \mathrm{hPa}$ in (a) January 01, 2007 and (b) January 20, 2007.

different states of the wave pattern in the middle of the troposphere on different days. The point of this graphic is to demonstrate that when the pattern changes, its impacts will be felt around the world. The dashed lines on the figure represent 'troughs' (low pressure systems) or regions where significant weather can be expected. While these patterns shift daily, there is an overall mean state.

An analysis of the last 50 years of data contained in the NCEP-NCAR reanalysis was accomplished by Powell and $\mathrm{Xu}$ [9]. The analysis was performed in an attempt to discriminate between potential climatological or decadal wave states. In their analysis, the ten strongest (top-10) amplitude waves and the ten weakest (weak-10) amplitude waves over the 50-year period were analyzed for common characteristics. Figure $\mathbf{2}$ is based on their

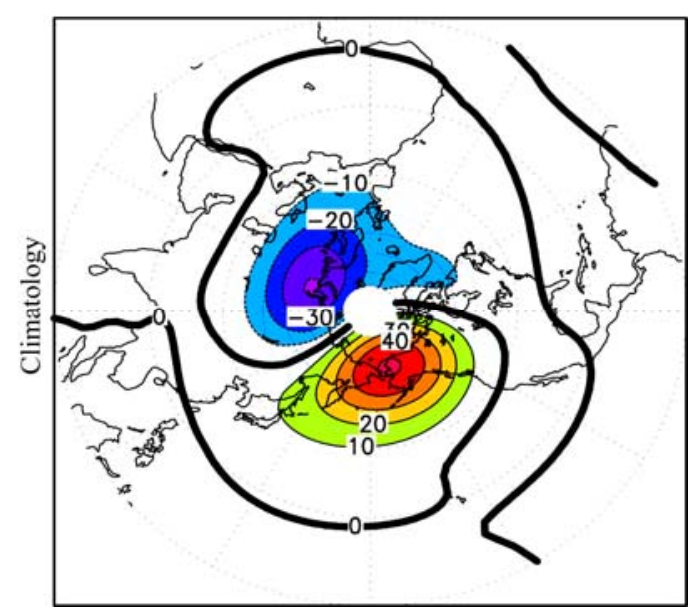

(a)

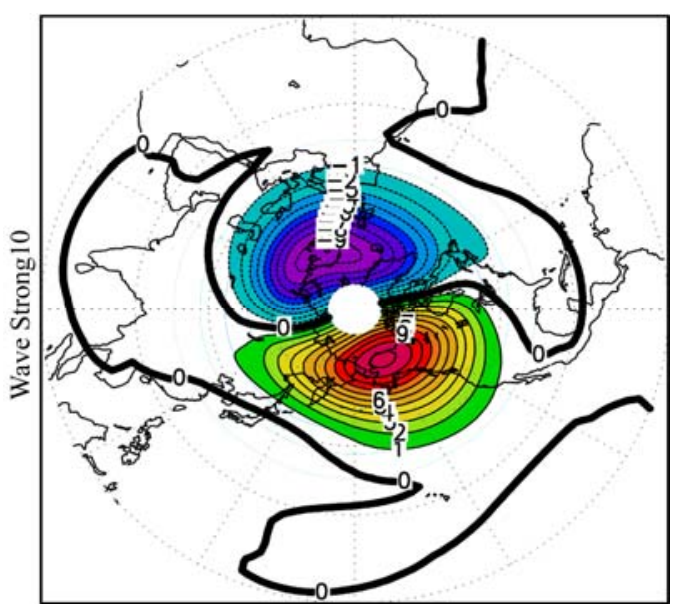

(b)

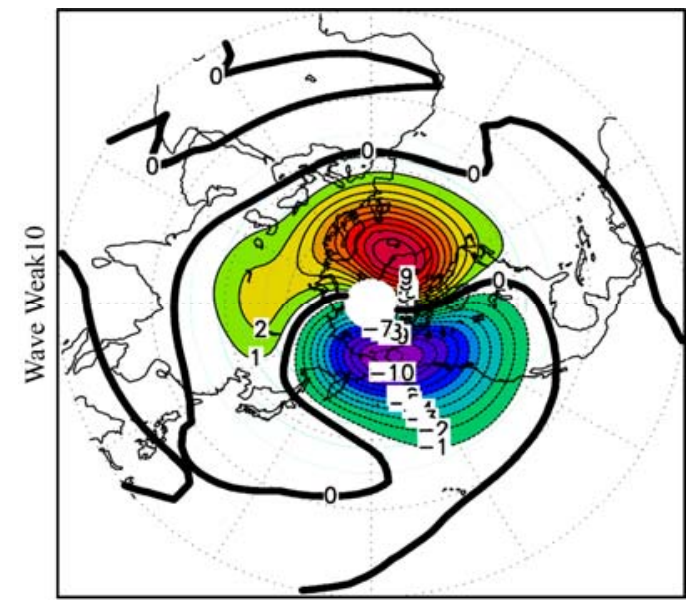

(c)

Figure 2. Stratospheric height climatology, and the composite stratospheric height $(30 \mathrm{hPa})$ during the top 10 strongest and weakest amplitude planetary wave years incorporating wavenumbers 1 thru 5. (a) climatology, (b) anomaly in top 10 strongest years, (c) anomaly in top 10 weakest years. 
work and shows wavenumbers 1-5 for the strong-10 wave pattern with its positive anomaly (difference from the mean state) over the polar Pacific and its negative anomaly over the polar Atlantic similar to the climatological wave pattern. For the weak-10 waves, see Figure 2 where the stratospheric height climatology, and the composite stratospheric height ( $30 \mathrm{hPa}$ ) during the top 10 strongest and weakest amplitude planetary wave years incorporating wavenumbers 1 thru 5 are shown (a) climatology, (b) anomaly in top 10 strongest years, (c) anomaly in top 10 weakest years anomaly. This pattern was essentially a reversal of the climatological anomaly (a change of phase) occurs between the strongest and weakest wave energies. This indicates that changes in the northern hemispheric wave pattern may affect every ocean and land mass at approximately the same time in a manner that can be readily analyzed.

More specifically, Figure 2 shows the climatological mean state for the period 1948-2008 for wavenumbers 1-5 at $30 \mathrm{hPa}$. The longest atmospheric wave (wave -number 1) can be represented by one low (trough) and one high (ridge) pressure area as it circles the globe. Wavenumber 1 is also the atmospheric wave with the most energy and greatest amplitude. As a result, the northern hemispheric wave pattern anomalies predominantly reflect changes in wavenumber 1 and this information will be used to interpret changes in the regime shift periods.

In this research, the focus is to determine how the 'average state' between regime shifts may have been affected over decadal length periods. Decadal changes in the atmospheric waves will affect the winds and temperatures around the globe and provide time for a significant response to develop. Each region could be affected differently depending on the wind speed, the wind direction relative to the coastline, and other factors like atmospheric stability for example. In this instance, the physical atmospheric changes (wave amplitude, wave phase, and its impact on surface wind stress) and the response of the ocean to the changing surface stress is analyzed in a simple and direct fashion. This simple linkage is thought to be the most likely way the wave pattern will affect the ocean system and subsequently the ocean ecosystems.

Changes in the northern hemispheric wave pattern have been associated with the Pacific Decadal Oscillation (PDO) and the North Pacific Index (NPI). The Pacific Decadal Oscillation is defined as the leading principal component (PC) of the monthly SST anomalies in the North Pacific Ocean [10] and the North Pacific Index is defined as the area-weighted sea level pressure over the region $30^{\circ} \mathrm{N}-65^{\circ} \mathrm{N}, 160^{\circ} \mathrm{E}-140^{\circ} \mathrm{W}$ [11]. Both the PDO and the NPI reflect changes in the northern hemispheric wave pattern and their potential influence on the
Pacific ocean. The PDO and NPI have been used by numerous authors [12,13 and references therein] as an indication of possible connections or forcings related to various physical and biological parameters. Since the PDO and NPI are related to the northern hemispheric wave pattern, it makes sense that many correlations (both and positive and negative) have been associated with these indices. For this analysis, more detail than can be provided by an index is required. As a result, this research has centered on the actual wave pattern and its decomposition via Fourier components - in particular wavenumbers 1-6. By comparing wave pattern changes attributed to the strongest atmospheric waves, it may be possible to discern significant wave pattern changes, and the winds associated with them. As the winds change, the coupling to the ocean will be affected along with the ocean ecosystems. This simple, direct, and brief summary provides the foundation for the following abrupt climate regime shift analysis.

\section{Identification of the Regime Shifts}

Numerous studies [12,13 and references therein] have used the PDO and NPI in their analyses in an attempt to demonstrate when a regime a shift will occur. Periods where the PDO and NPI indices cross over the 'zero' point tend to be favorite locations in the graphs for identifying possible regime shifts. The question is whether or not changes in these indices adequately reflect the impacts on regional ecosystems. Figure 3 shows both the PDO and NPI indices graphed together in (b). The correlation coefficient between the PDO and NPI is approximately 0.72 and indicates it accounts for approximately $51 \%$ of the variability between the two indices. This implies both indices are likely measuring essentially the same core atmospheric variation. However, when the two indices are compared against the fish landing data from NOAA's Southwest Fisheries Science Center, the correlation of the fish catch with the PDO is only 0.11 (accounting for only $1.2 \%$ of the variance in the fish landing data) and is only 0.03 for the NPI (accounting for $0.0009 \%$ of the variance in the fish landing data). One would expect a much greater correspondence between the PDO and NPI with the fish landing data if they had a significant cause-effect relationship. Another possibility is that the fish catch and wave amplitudes are directly related and the correlation analysis with the PDO and NPI indices does not reflect the relationship adequately. One outcome of this analysis will be to ascertain whether the PDO/NPI indicies are robust enough to reflect the association between the oceans and fisheries for a specific basin like the Pacific, or whether a more detailed analysis is required to assess linkages between the at mosphere, ocean and fisheries. 
To determine whether a stronger cause-effect relationship can be ascertained, a series of simple and direct observational analyses will be performed. The first step in the analysis process is developing a consistent approach for identifying the abrupt climate shifts. Once the shifts were identified then an analysis was performed by aggregating the data between the identified regime shift dates to understand the regime differences. By analyzing the approximately decadal length changes, an interpretation about the forcing mechanism(s) can be made.

To identify the regime shifts, the fish landing data were analyzed for abrupt shifts using the period means similar to Lehodey [6]. Figure 4 shows the results of the analysis with regime shifts occurring at approximately

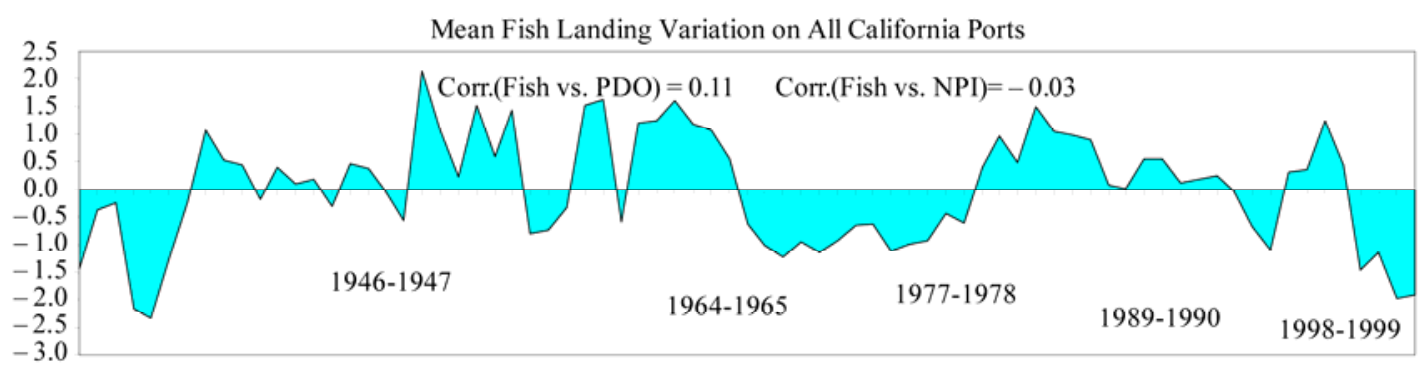

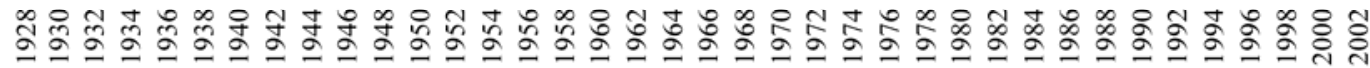

(a)

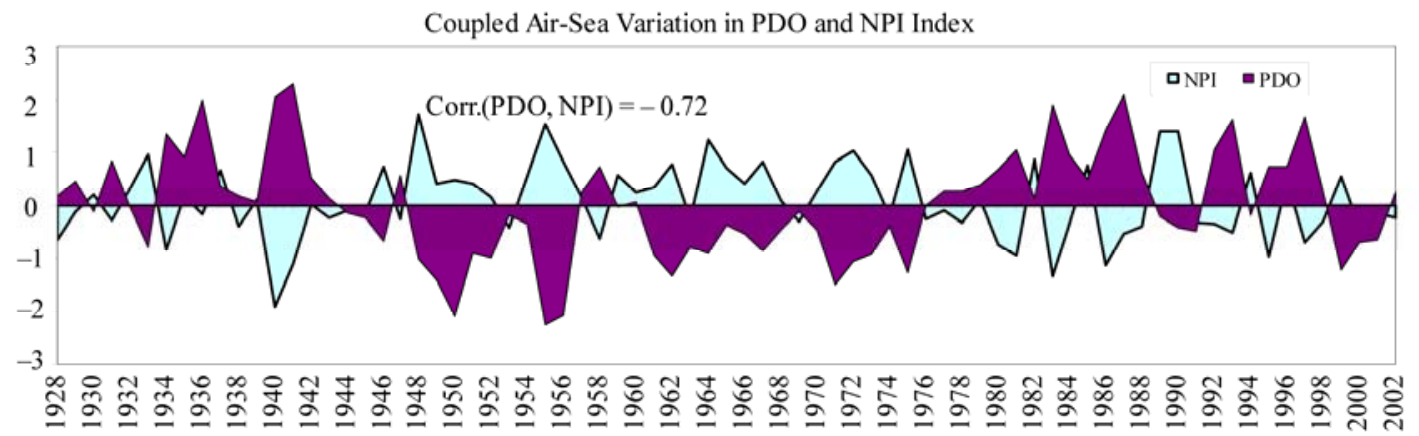

(b)

Figure 3. Time series of (a) normalized amounts of the total fish landing of California ports and (b) Pacific Decadal Oscillation (PDO) and North Pacific index (NPI). The correlations are calculated between these time series. The dashed line indicats the time of regime shift occurrence.

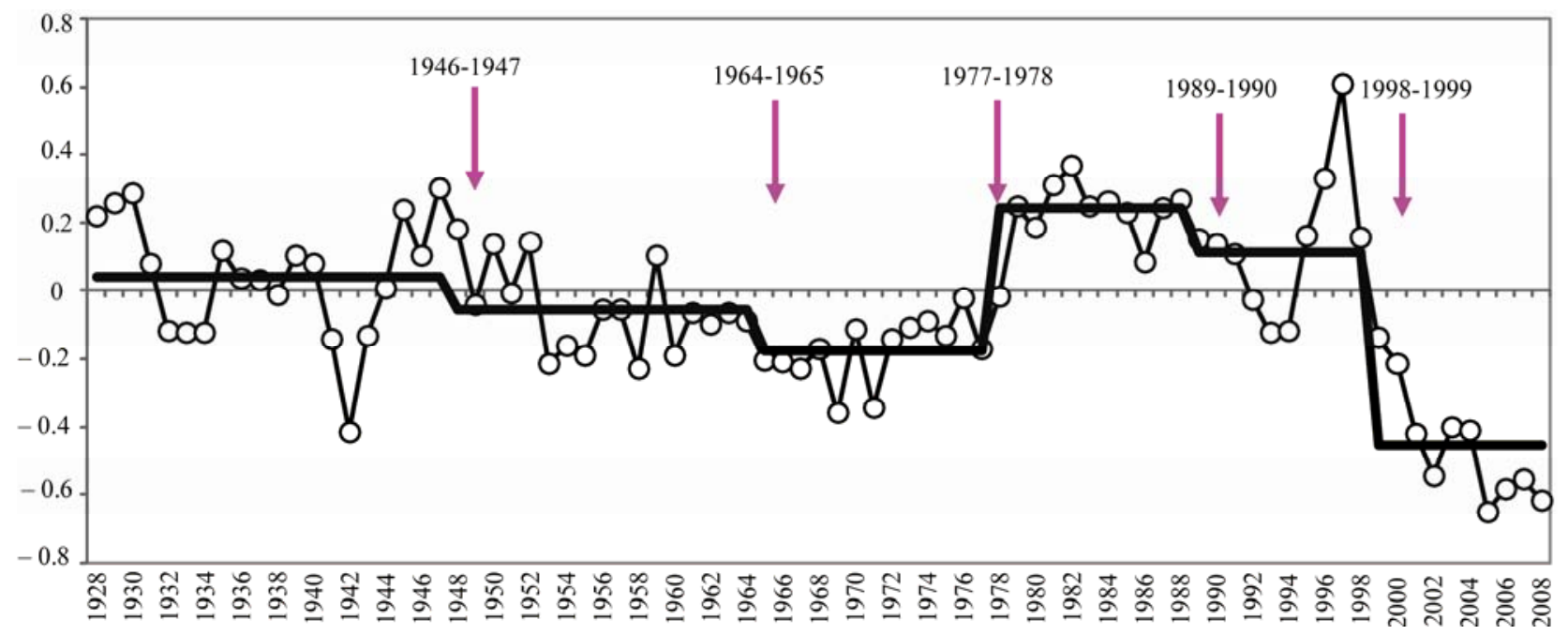

Figure 4. Normalized California's fish landings from 1928-2008 for total amounts of the 31 fish species. The heavy line indicates the decadal average for the periods of 1928-1947, 1948-1964, 1965-1977, 1978-1988, 1989-1998 and 1999-2008. 
1946-1947, 1964-1965, 1977-1978, 1989-1990 and 1998 -1999. The basic assumption was that the biological response is more sensitive to physical change than can be adequately discriminated based on our current understanding of the physical forcings. To ensure the analysis represents actual regime shift periods, a consistency check was performed using peer reviewed publications. Table 2 reflects the collection of regime shift information from the literature where researchers used a variety of techniques, analytical methods, as well as both physical and biological responses as regime shift indicators. The results in Table 2 verify the dates of regime shifts from the fish catch/stock analysis and possibly also identify regime shifts that may have different forcing mechanisms than the ones identified from the fish landing data.

Based on the literature analyses, the authors concluded that not all the regime shifts identified appear to be due to the same fundamental cause-effect coupling. However, assuming that the change in fish catch reflects a consistent biological response to a set of physical changes, the fish landing regime shifts were corroborated by the literature. The fish landing regime shift dates were used to categorize the climate shift years in order to determine whether a consistent, simple and direct forcing can be ascertained from the independently gathered data sets and analyses in the published literature.

\section{Abrupt Change in the Atmosphere, Ocean and Fisheries}

1) Atmosphere

Using the regime shift dates from the fish landing (catch) analysis, the northern hemispheric wave pattern was analyzed to determine whether the typical cause-effect mechanism (atmospheric forcing, ocean change and fishery changes) could explain any potential linkages between the data sets. Fourier analysis of wave numbers 1-6 derived from the height field of the NCEP-NCAR reanalysis shows the pattern in Figure 5 when the data are grouped according to the regime shifts dates obtained from the fish landing analysis. Figure 5 shows the (a) mean state of the atmospheric height field over the entire period (1948-2008) and the anomalies from that state for the periods between each abrupt shift date: (b) 1948-1964, (c) 1965-1977, (d) 1978-1988, (e) 1989-1998, (f) 1999-2008. For each period, the primary positive anomaly over the polar region is either similar to the climatological state or generally opposes it. Starting with the 1948-1964 period, the pattern opposes the mean climatology and is consistent with a weak wave pattern as shown in the weak-10 analysis. Each of the subsequent periods (1965-1977, 1978-1988, and 1989-1999), show a reversal of the northern hemispheric wave pattern anomalies from one period to the next. Only the last period representing 1999-2008, does not show a complete reversal in the pattern. However, 1999-2008 is clearly

Table 2. Table of regime shifts identified in the literature from predominantly marine analyses.

\begin{tabular}{|c|c|c|}
\hline Regime Shift Years from Literature & $\begin{array}{l}\text { Overland Analysis } \\
{[17]}\end{array}$ & $\begin{array}{l}\text { Ocean, Fisheries, and Related Atmospheric Literature Identifying } \\
\text { Regime shifts [reference number] }\end{array}$ \\
\hline \multirow[t]{2}{*}{ 1924-1925, 1925,1925-1926 } & $1924-1928$ & {$[23],[24],[25],[29],[32],[33],[37],[2],[14],[47],[18],[53]$} \\
\hline & 1934-1935 & [5] \\
\hline $1941-1942$ & 1943 & [25] \\
\hline 1945-1946, 1946-1947, 1947-1948 & 1946-1949 & {$[23],[24],[32],[33],[37],[38],[14],[18],[53]$} \\
\hline 1950 & 1953-1955 & [2] \\
\hline 1957-1958,1958-1960, 1959-1960 & $1957-1960$ & {$[25],[29],[47],[18],[53],[64]$} \\
\hline 1963-1964, 1966-1967 & $1961-1966$ & {$[5],[64]$} \\
\hline 1967, 1968-1969, 1970-1971 & $1969-1974$ & {$[40],[18],[53],[57]$} \\
\hline 1976-1977,1976, 1977 & 1975-1980 & 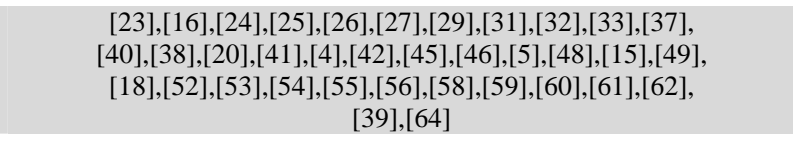 \\
\hline 1982-1985, 1983-1984 & 1981-1985 & {$[43],[46],[5],[15],[64]$} \\
\hline 1988-1989, 1985-1988 & $1987-1990$ & $\begin{array}{c}{[26],[27],[2],[31],[37],[40],[38],[41],[43],[44],[45],[46],[5],[48],[15],[} \\
49],[18],[50],[51],[53],[54],[55],[56],[39],[51]\end{array}$ \\
\hline 1992 & 1991-1995 & {$[36],[15]$} \\
\hline 1998, 1997, 1999 & 1996-1999 & $\begin{array}{c}{[27],[28],[30],[2],[33],[35],[36],[37],[38],[41],[14],[44],[5],[48],[50],[} \\
39],[64]\end{array}$ \\
\hline 2002, 2003 & 2000-2004 & {$[14],[15]$} \\
\hline
\end{tabular}

The shaded rows in the table correspond with the 50-year cycle (25-year half cycle) identified by Minobe. Papers that identified regime shifts within a decade or 'mid-70s', for example, were not included in this summary unless they also specified a narrow range of years for any shifts or provided information in the paper that allowed the reader to ascertain a narrow range of dates for the shift(s) discussed. 


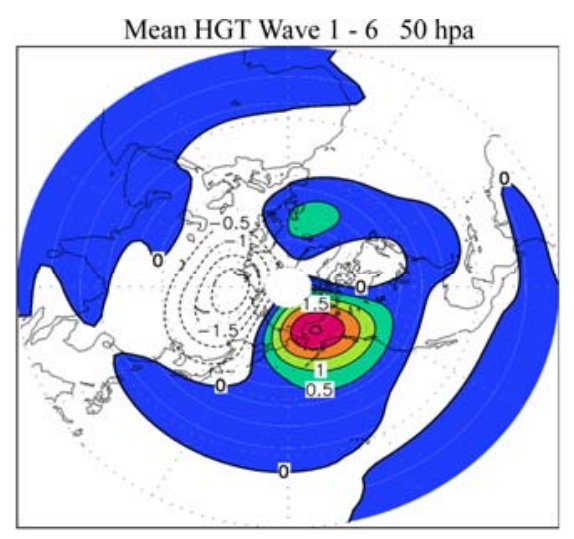

(a)

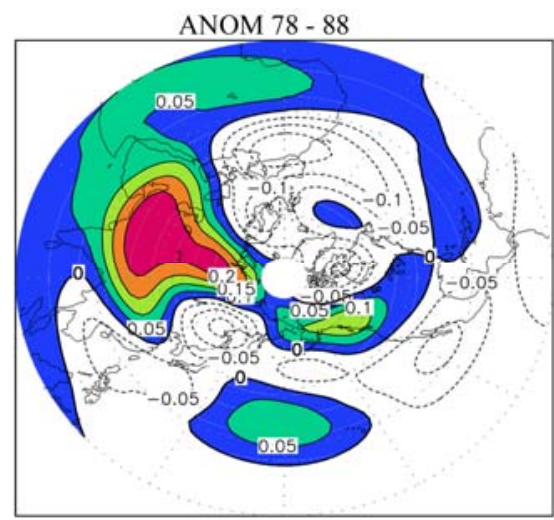

(d)

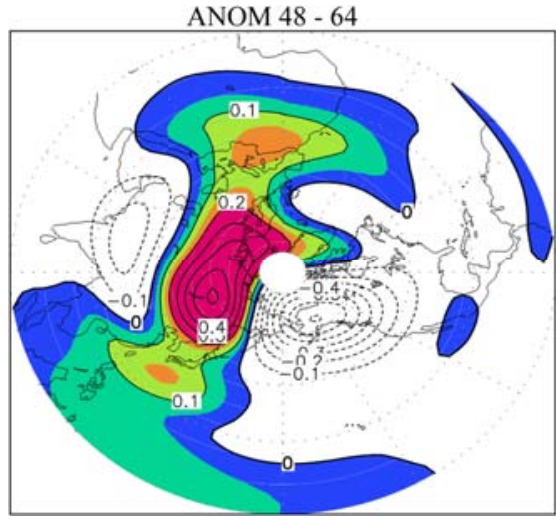

(b)

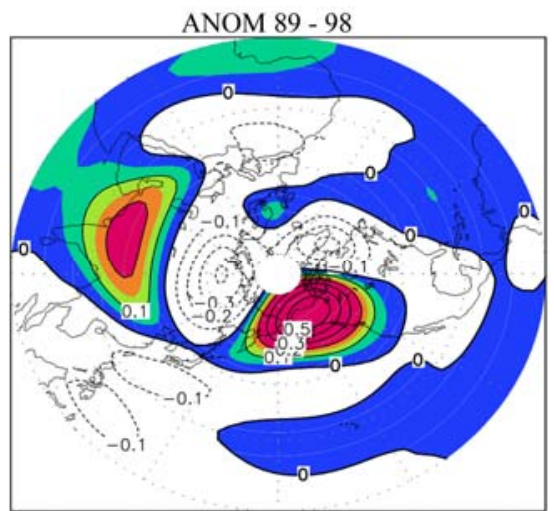

(e)

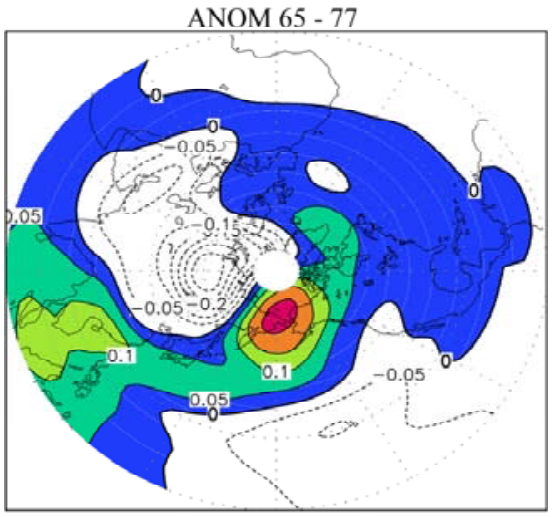

(c)

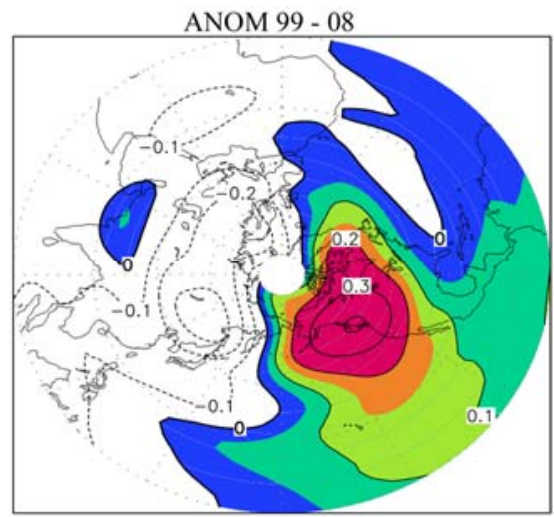

(f)

Figure 5. Reconstructed planetary wave pattern using geopotential height and wavenumbers 1-6 at 50hPa in NCEP/NAR reanalysis. (a) Mean of 1948-2008, and the anomalies for each of the following periods: (b) 1948-1964, (c) 1965-1977, (d) 1978-1988, (e) 1989-1998; (f) 1999-2008. Units: gpm. Shaded areas indicate positive anomalies.

weaker in terms of the magnitude of the anomalies. Also, the 1999-2008 period may be too long since another regime shift was possibly identified in 2003 [14,15]. Since the wind patterns will change in accordance with these shifts in atmospheric wave pattern anomalies, it is reasonable to assume the ocean will show corresponding signs of change. The northern hemispheric wave pattern is indicative of wind changes throughout the depth of the atmosphere and, as such, the surface wind stress patterns should be reflected in any change observed. Note, the wave pattern rotates as one goes higher/lower in the atmosphere but the 'stacked' relationship remains coupled; the pattern will look different only by some degree of rotation for any specified altitude in the atmosphere. As one goes from high in the atmosphere to close to the surface, the wave pattern may show predominantly land effects due to mountains, surface friction, etc. However, over the oceans, the atmospheric pattern should be indicative of the northern hemispheric wave changes and result in consistent changes in the ocean patterns. While each ocean basin (region) will be affected by the north- ern hemispheric wave pattern, how it is affected by the pattern may differ by ocean basin. For this analysis, the connection is limited to the north Pacific ocean as the trial case.

2) Ocean

Figure 6 shows the surface wind (a thru f) and sea surface temperature (SST) patterns ( $g$ thru i) over the Pacific ocean including the period prior to 1948 (19281947) since a regime shift was identified in the literature as occurring in 1947-1948. For each period, the surface wind stress anomalies and SST anomalies are shown from the COADS data and the NCDC Extended Reconstructed Sea Surface Temperatures. When the longest fetch across the ocean is west to east, a cold SST anomaly tends to occur over the northwest and central Pacific and a warm anomaly forms along the west coast of the United States (eastern Pacific). When the longest ocean fetch is from east to west, a warm SST anomaly tends to occur over the northwest and central Pacific and a cold anomaly forms along the west coast of the United States. The wind stress is more than the simple advection 
COADS ANOM 1928-1947

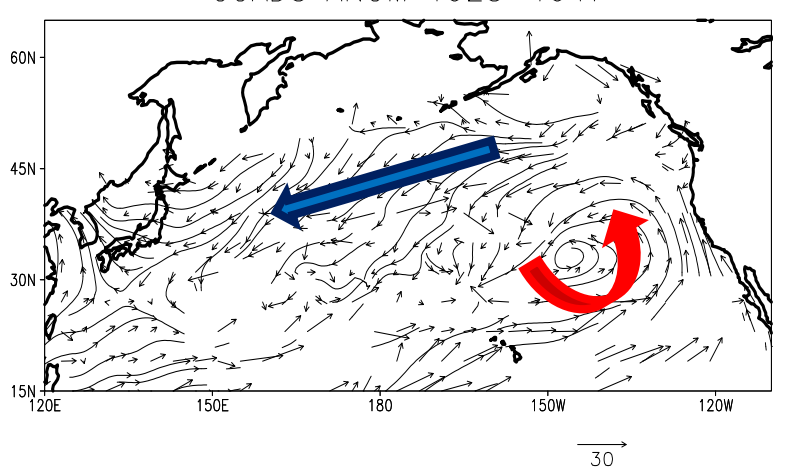

(a)

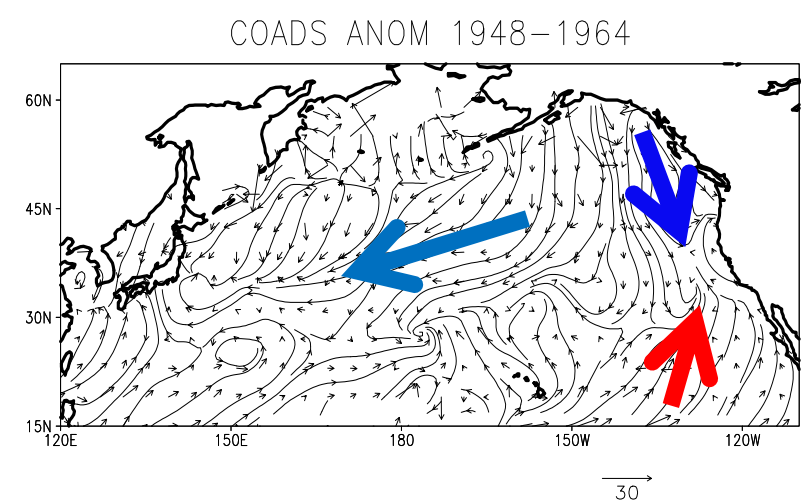

(b)

COADS ANOM 1965-1977

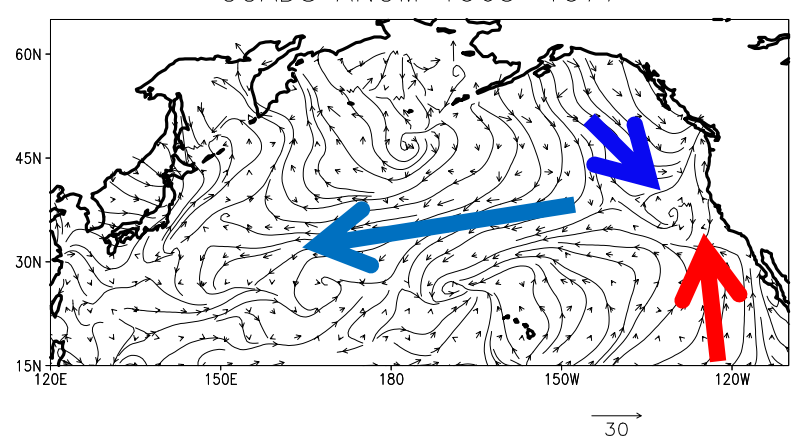

(c)

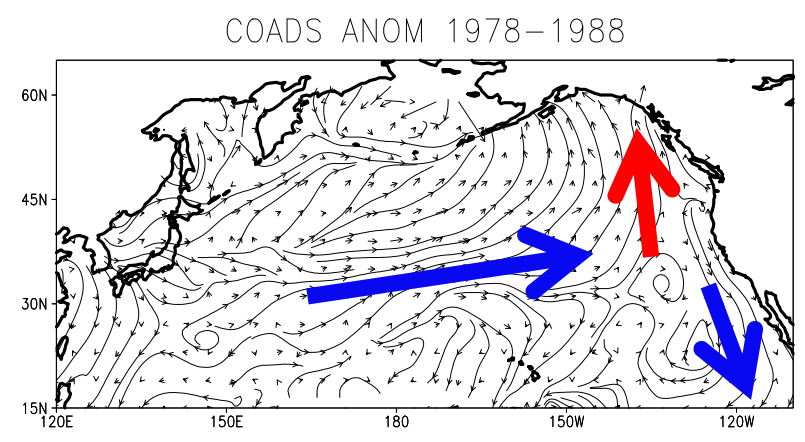

(d)

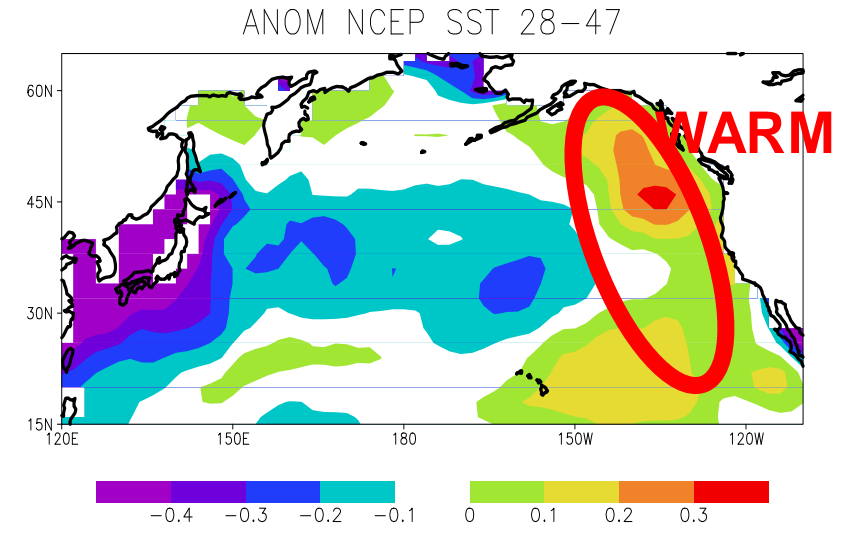

(g)

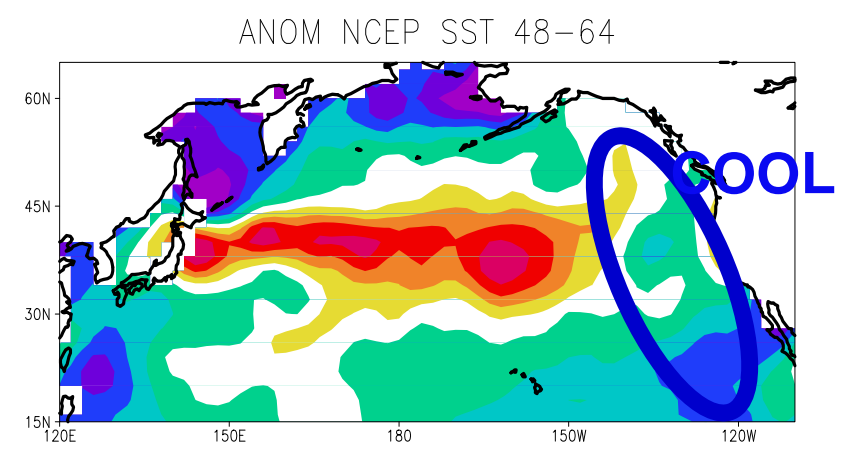

(h)

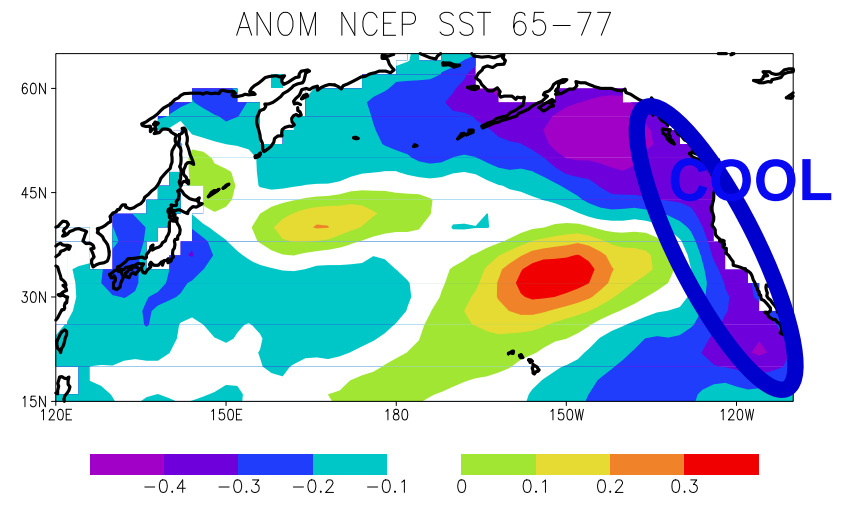

(i)

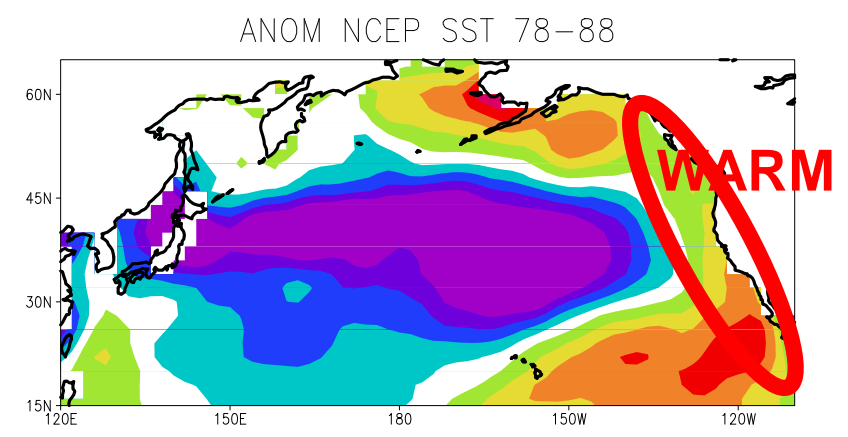

(j) 


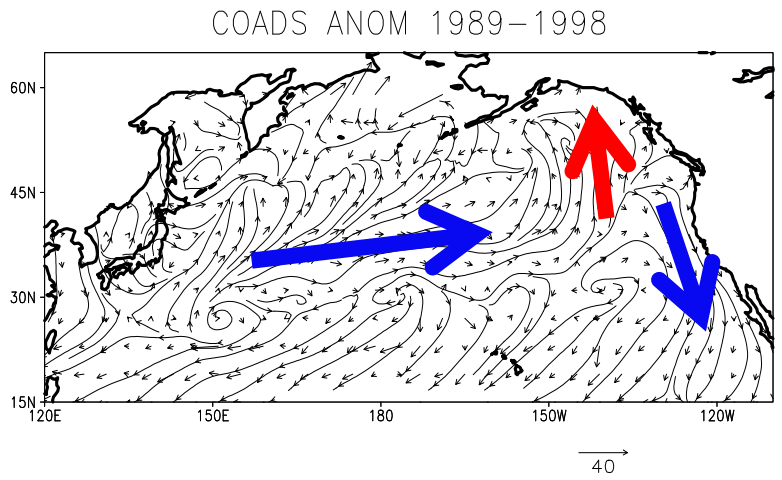

(e)

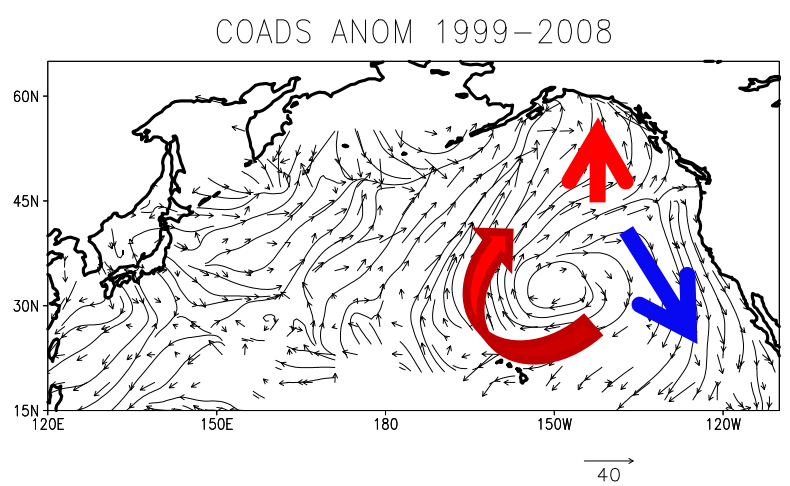

(f)

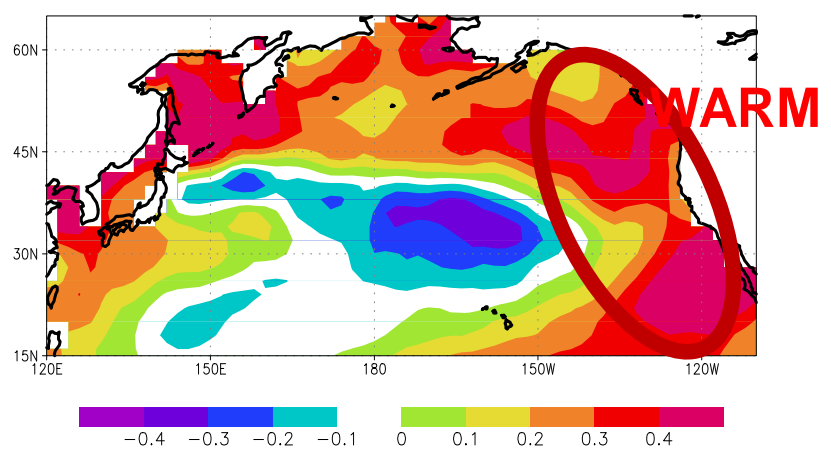

$(\mathrm{k})$

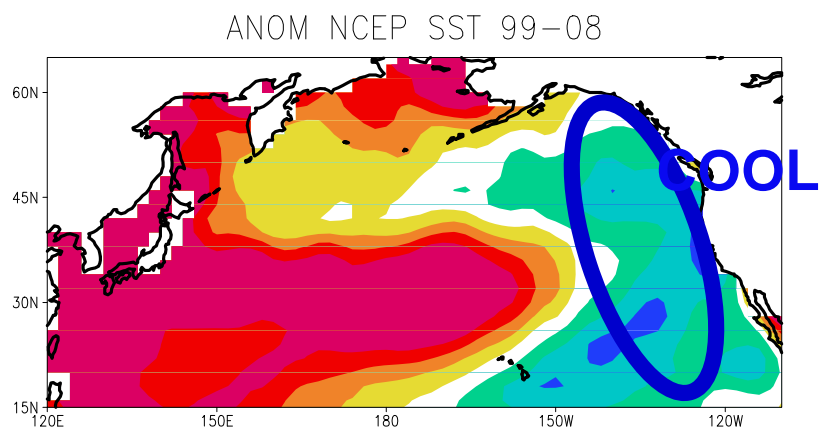

(l)

Figure 6. The pattern of the surface wind stress (units: $\mathbf{d y n} \mathbf{~ c m}^{-2}$ ) and sea surface temperature (units: ${ }^{\circ} \mathrm{C}$ ) anomalies over the north Pacific ocean. Left panel: surface wind stress (a) 1928-1947, (b) 1948-1964, (c) 1965-1977, (d) 1978-1988, (e) 1989-1998, (f) 1999-2008; Right panel: sea surface temperature (g) 1928-1947, (h) 1948-1964, (i) 1965-1977, ( j) 1978-1988, (k)1989-1998, (l) 1999-2008.

of water as the impact of El Nino has demonstrated off the South American coast. El Nino events also affect upwelling/downwelling, for example, that can have a marke impact on the fishing off South America. The El Nino effects are related to the wind and the direction it blows relative to the shoreline which can cause periods of upwelling or downwelling that impact the fish populations. Similarly, changes in the northern hemispheric wind stress are expected to impact multiple facets of the ocean current system. What has been demonstrated in this analysis is the impact of a major atmospheric pattern change between decadal periods on a core ocean variable (SST) which in turn can have major ecosystem impacts.

\section{3) Fisheries}

The general change in ocean temperature shown in Fig. 6 between the eastern and western Pacific is consistent with previous research [2,4,5], where the out-of-phase impacts of SST on the sardine and anchoveta populations have been demonstrated. Further, Takasuka et al. [3] indicated that differences in spawning temperatures are a potential cause of the opposing populations of sardines and anchoveta in the same regions. While the analysis offers a possible explanation for the reversal of the sar- dine and anchoveta populations, a more general conclusion may be possible. If we assume that SST can impact the fisheries via a variety of pathways (spawning temperatures, food availability via upwelling/downwelling, etc), then the fish landings should subsequently show corresponding changes in multiple fish populations.

In Figure 7, the 31 individual species of fish landings available from NOAA's Southwest Fisheries Science Center were analyzed for those that improved or worsened in each regime period. Table 1 identifies the number plotted for each species of fish shown in Figure 7. The fish that increased (decreased) in normalized landings were plotted together. A red line was drawn between those that increased and decreased to help highlight the impact of the abrupt shifts on the number of fish species affected. The red line shows the relative change in biological impact on the ecosystem; in this case, it is the ecosystem off the California coast (the eastern Pacific). During warm anomaly periods, the number of fish species with increased normalized landings is greater than during the cold anomaly periods and vice versa. While this analysis is for a single region/ecosystem, it is relevant for understanding the global scale chain of the 

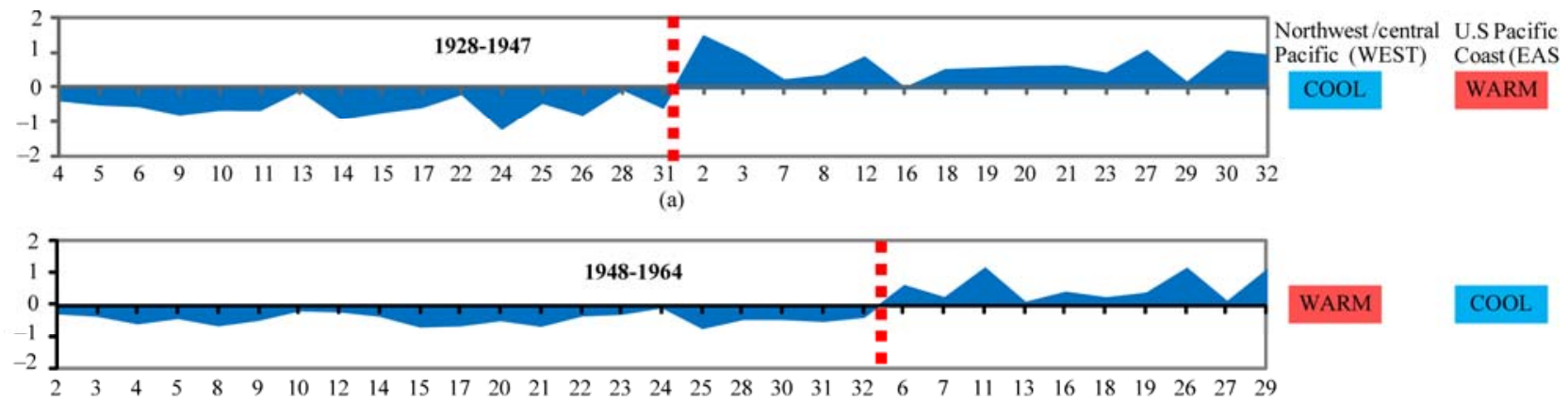

(b)

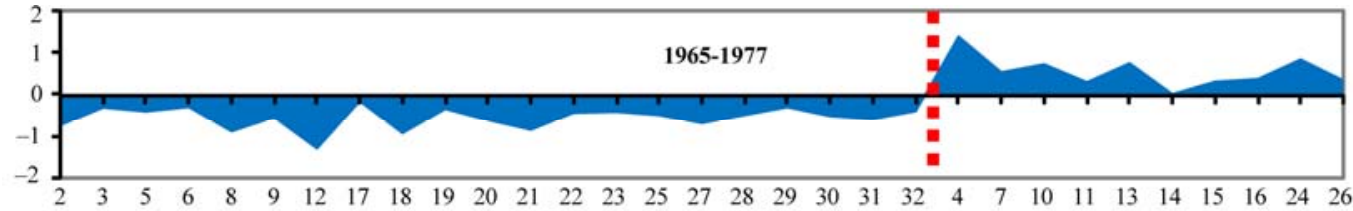

(c)

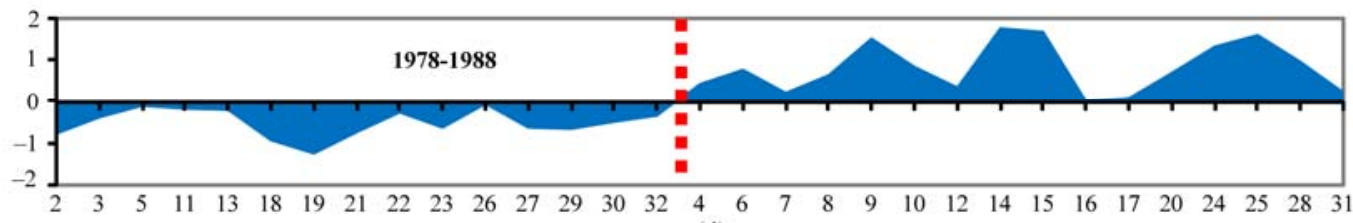

(d)

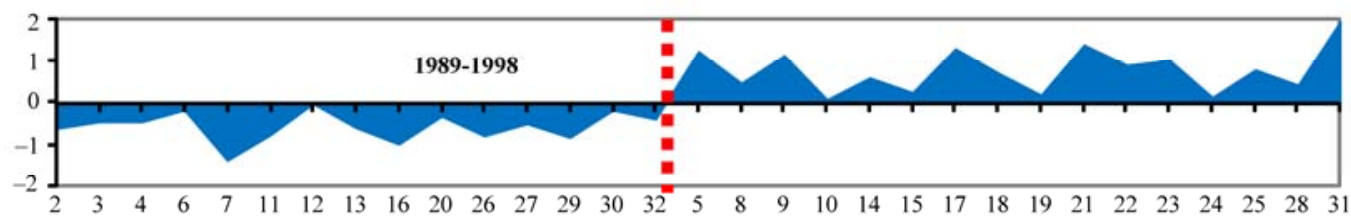

(e)

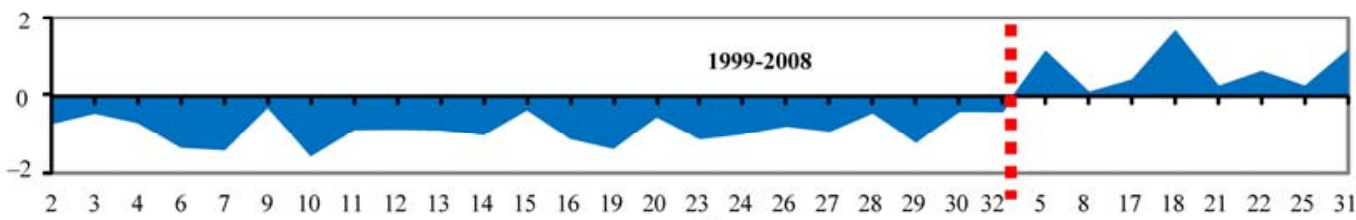

(f)

Figure 7. Average normalized fish landing amounts for the U.S. west coast for each species in the periods coincident with abrupt climate regime shifts. (a) 1928-1947, (b) 1948-2008, (c) 1965-1977, (d) 1978-1988, (e) 1989-1998, (f) 1999-2008. The X-coordinate number indicates the code for the fish species marked in Table 1. "COOL" and "WARM" indicates the regional SST anomaly.

events that cause regional ecosystem change. As surmised by Chavez et al. [2], it appears there is a simple and direct mechanism (atmospheric state change) which induces wind stress changes impacting the ocean that result in SST changes (and probably other impacts) that could affect biological activity regionally.

\section{Discussion}

The purpose of this paper is to demonstrate that a change in large scale forcing could produce simple and direct impacts from the atmosphere to the ocean to ecosystems to fish landings. These impacts were shown across the dates of each regime shift identified from a biological marker (fish landings) and corroborated by other manifestations of change in an ecosystem from the literature. Many factors have been connected with regime shifts. Ebbesmeyer [16] and Overland et al. [17,18] showed possible connections with 30 to 100 physical, biological and climate variables. Collie, et al. [19] pointed out that smooth, abrupt, and discontinuous shifts can be identified on the basis of different patterns in the relationship between the response of an ecosystem variable (typically biological) and some external forcing. Kim, et al. [20] demonstrated that specific parameters such as nitrogen levels, upwelling, and thermocline depth can be associ- 
ated with regime shifts. Aebisher, Coulson and Colebrook [21] discussed how temperature and wind stress variations affect plankton production which can propagate up the food chain and impact fish populations. With many factors potentially affecting an ecosystem, it should be obvious that not all fish species will respond similarly to the same physical change in the environment; some fish may be affected by specific changes such as food availability, the depth where the specific fish species predominantly lives, spawning temperatures, and many other factors. Consequently, a specific external forcing may also be difficult to identify. As a consequence, the analysis approach used the more traditional atmospheric forcing of the ocean via wind stress as the general mechanism combined with the simple approach of looking at how many fish species improved or declined for identifying regime shifts. The results show clear changes in fish populations across the regime shift boundaries consistent with large-scale physical forcing changes - in this case changes in wind stress and sea surface temperature.

The overall chain-of-impacts were shown using a 'top-down' logic (from atmosphere to ocean to fish) to help readers appreciate the traditional linkages between atmospheric wind and ocean current changes as one large-scale system acts on another. The global scale wave amplitude approach provided a method of showing the abrupt changes in the atmosphere via its relatively simple pattern of change. The northern hemispheric wave amplitude is directly related to the wind which impacts the surface wind stress, ocean currents, SST, advection and upwelling/downwelling. The easiest and most measured ocean parameter to analyze for this project was the SST. The changes in the SST explain the general pattern of opposing ocean characteristics in the eastern Pacific versus the western Pacific which could result in the changes identified by many studies [1-5] in terms of sardine and anchoveta in the western and eastern Pacific for example. Temperature change has been implicated as a mechanism for the out-of-phase sardine and anchoveta response through the spawning temperatures which impact survival rates of these two species [3]. However, more than one species of fish should be affected by the abrupt climate shifts and a single species change may not mark a climate shift. The fish landing data from NOAA's Southwest Fisheries Science Center provided the ability to link the fish population changes with the abrupt climate shifts and a common ecological chain via the ocean/ecosystem temperatures. The atmospheric pattern over the Pacific can be generally divided into two basic patterns which essentially reflect predominantly wavenumber 1 changes so that when the pattern reverses across a regime shift, regional SST varia- tions across the Pacific occur synchronously with a cascading effect on the fisheries populations. Figure 8 shows the basic near-surface atmospheric patterns, deduced from the COADS analysis, that appear to result in the east-west temperature shifts in the Pacific. These changes appear to impact the populations of certain species of fish. These changes appear to be dominated by the long easterly or westerly fetches across the Pacific that set up a specific SST pattern in the Pacific. However, the Pacific pattern is also influenced by a circular wind pattern in the southeast Pacific. The southeast Pacific circular wind pattern can circulate either clockwise or counter-clockwise and helps generate an SST pattern similar to the long easterly and westerly fetch wind patterns. This is probably due to unusually strong and southward displacement of the northern hemispheric wave pattern in the eastern Pacific.

The net result from this analysis is that northern hemispheric wave pattern changes can produce wind stress changes that generate SST anomalies which in-turn can affect the fish populations (as determined from the analysis of the California coastal ecosystem in this study). The impact of SST change on fisheries populations is documented in many journal articles. One question that remains is whether the climate shifts are due to northern hemispheric wave pattern changes or due to other possible forcing mechanisms like El Nino.

A discussion of abrupt climate shifts and their impact on the ocean is not complete without a discussion of El Nino impacts. El Nino occurs every 5 to 7 years and with a typical 2-3 year span of intensification which could be related to nearly every regime shift identified. However, the pattern of temperature change in the Pacific Ocean is not consistent with the impact of El Nino but aligned with mid-to-high latitude atmospheric forcing associated with the PDO or NAO. The work of Schneider and Cornuelle [22] and Lehodey et al. [6] show convincing evidence that El Nino tends to most impact the equatorial Pacific and have its impacts described as annual, nonseasonal and catastrophic while the broader climate impacts are associated with atmospheric forcing are usually ascribed to the PDO and NAO. The work of Schneider and Cornuelle [22] use models, observations and statistical analyses to demonstrate the difference in effects from an El Nino forcing compared to a PDO type atmospheric forcing. Their results for the PDO impact regions in the Pacific are in very good agreement with the patterns shown for this analysis using the COADS data and the NCDC Extended Reconstructed Sea Surface Temperatures. Consequently, it supports the contention the atmospheric-ocean-fisheries impacts shown in this paper are due primarily to mid-high latitude atmospheric 
TOP ROW: Wind Pattern One and the resulting warm and cool anomalies
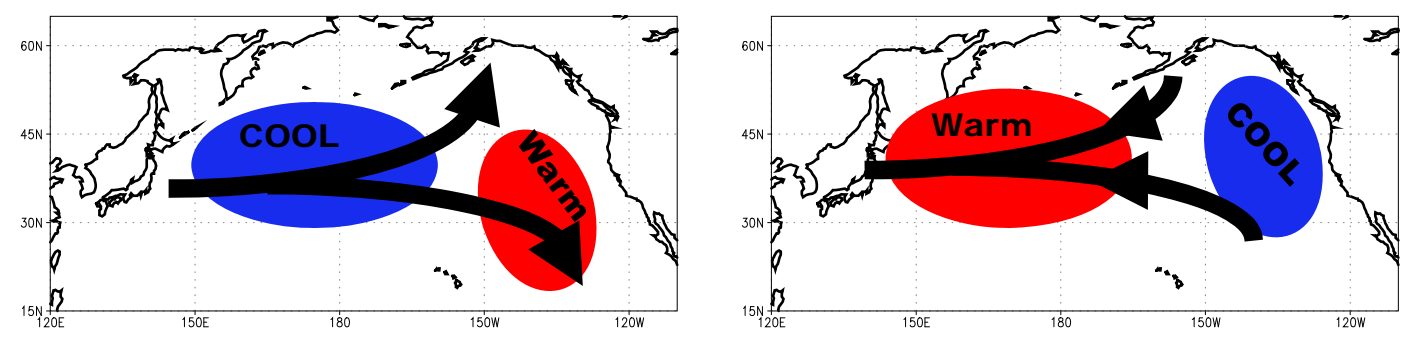

BOTTOM ROW: Wind Pattern Two and the resulting warm and cool anomalies
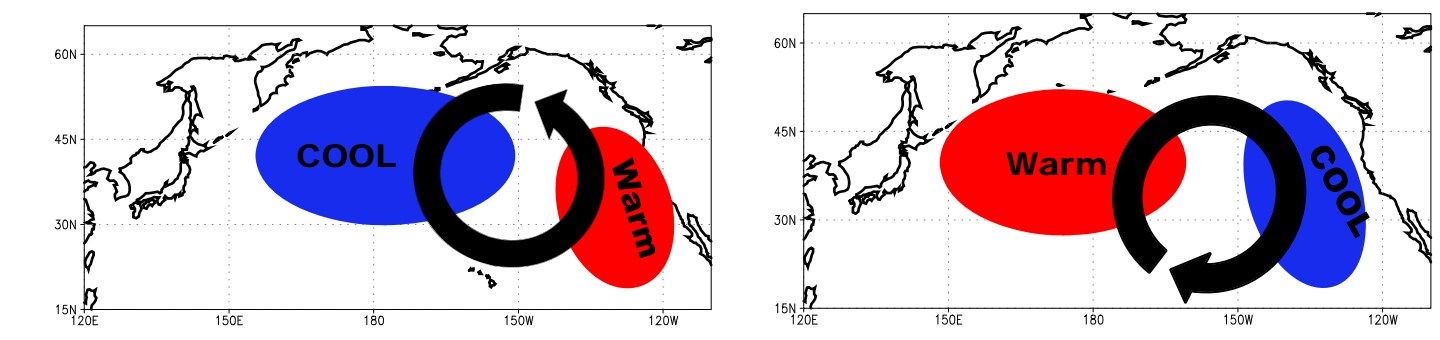

West is Cool with fewer fish catch

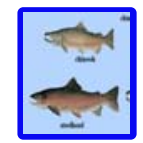

East is Warm with greater fish catch

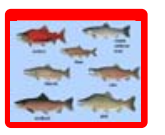

West is Warm with greater fish catch

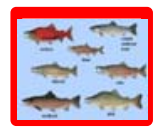
East is Cool with
fewer fish catch

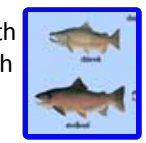

Figure 8. Scheme diagrams of the two types of wind stress patterns lead to opposing warm and cool anomalies that affect major ecosystems fish catch and stock numbers. "WARM" regime has generally positive ecosystem impacts on fish catch/stock and "COOL" regime has generally negative impacts. The "arrow" indicates the wind flow direction over the ocean surface.

forcing which cascades through ocean physical changes into ecosystem biological variations.

As an additional note, Lehodey [6] points out the well known 'see-saw' effect between Greenland and northwestern Europe due to opposite atmospheric conditions between the eastern and western sides of the northern North Atlantic. This effect is often referred to as the North Atlantic Oscillation (NAO). The effect of wavenumber 1 shown in this analysis also impacts the Atlantic region similarly; furthering the case that the atmospheric wave pattern is the prime candidate for the global scale forcing mechanism that may cause the fish populations around the world to change in synchrony.

\section{Summary}

Following the suggestion of Chavez et al. [2] that the changes in fish populations were likely due to large-scale, simple, and direct forcing, an analysis was constructed to demonstrate whether this was a plausible assumption. Based on the analysis of the atmospheric northern hemispheric wave pattern forcing, consequential SST changes and the subsequent impacts on fish populations in the eastern Pacific, Chavez's [2] premise appears to hold. In fact, it appears the global scale wave pattern and its amplitude may be the key forcing mechanism that causes near synchronous impacts in the world's oceans and sub- sequently changes in the fish populations and ocean ecosystems.

The follow-up research is intended to determine whether the changes seen in the northern hemispheric wave pattern and the resultant impacts in the Pacific basin can be more generally applied to other ocean basins and their ecosystem fish population changes. The current literature suggests a synchrony of fish population changes in the major ocean basins.

\section{Acknowledgements}

The NCEP/NCAR monthly reanalysis data were obtained from NOAA/CDC web site. The SST and COADS datasets from the NCDC. The authors would like to thank these agencies for providing the data. Special thanks to Dr. Mason from the Pacific Fisheries Environmental Laboratory in the Southwest Fisheries Science Center of NOAA for the fisheries datasets that were provided.

This work was supported by the National Oceanic and Atmospheric Administration (NOAA), National Environmental Satellite, Data and Information Service (NESDIS), Center for Satellite Applications and Research (STAR). The views, opinions, and findings contained in this publication are those of the authors and should not be considered an official NOAA or U.S. Government position, policy, or decision. 


\section{References}

[1] T. Kawasaki, "Why Do Some Pelagic Fishes Have Wide Fluctuations in Their Numbers? Biological Basis of Fluctuation from the Viewpoint of Evolutionary Ecology,” FAO Fisheries Report, Vol. 291, 1983, pp. 1065-1080

[2] F. P. Chavez, J. Ryan, S. E. Lluch-Cota and C. M. Niquen, "From Anchovies to Sardines and Back: Multidecadal Change in the Pacific Ocean," Science, Vol. 299, 10 Jan 2003, pp. 217-221. doi:10.1126/science.1075880

[3] A. Takasuka, Y. Oozeki, H. Kubota and S. E. Lluch-Cota, "Contrasting Spawning Temperature Optima: Why Are Anchovy and Sardine Regime Shifts Synchronous Across the North Pacific?” Progress in Oceanography, Vol. 77, 2008, pp. 225-232. doi:10.1016/j.pocean.2008.03.008

[4] D. Lluch-Belda, R. A. Schwartzlose, R. Serra, R. Parrish, T. Kawasaki, D. Hedgecock and R. J. M. Crawford, "Sardine and Anchovy Regime Fluctuations of Abundance in Four Regions of the World Oceans: A Workshop Report," Fisheries Oceanography, Vol. 1, 1992, pp. 339-347. doi:10.1111/j.1365-2419.1992.tb00006.x

[5] B. DeYoung, R. Harris, J. Alheit, G. Beaugrand, N. Mantua and L. Shannon, "Detecting Regime Shifts in the Ocean: Data Considerations," Progress in Oceanography, Vol. 60, 2004, pp. 143-164. doi:10.1016/j.pocean.2004.02.017

[6] P. Lehodey, A J. Alheit, B M. Barange, C. T. Baumgartner, D. G. Beaugrand, E. K. Drinkwater, F. J. M. Fromentin, G. S. R. Hare, H. G. Ottersen, F. R. I. Perry, I. C. Roy, J. C. D. K. Van Der Lingen and F. Werner, "Climate Variability, Fish, and Fisheries," Journal of Climate, Vol. 19, 2006, pp. 1009-1029. doi:10.1175/JCLI3898.1

[7] Mason, J. E., "Historical Patterns From 74 Years Of Commercial Landings From California Waters,” CalCOFI Rep., Vol. 45, 2004, pp. 180-190.

[8] E. Kalnay, et al., "The NCEP/NCAR 40-Year Reanalysis Project," Bulletin of the American Meteorological Society, Vol. 77, 1996, pp. 437-471. doi:10.1175/1520-0477(1996)077<0437:TNYRP>2.0.CO ;2

[9] A. M. Powell and J. Xu, "Possible Solar Forcing of Interannual and Decadal Stratospheric Planetary Wave Variability in the Northern Hemisphere: An Observational Study," Journal of Atmospheric and Solar-Terrestrial Physics, 2011. doi:10.1016/j.jastp.2011.02.001.

[10] Y. Zhang, J. M. Wallace and D. S. Battisti, "ENSO-like Interdecadal Variability: 1900-93," Journal of Climate, Vol. 10, 1997, pp. 1004-1020. doi:10.1175/1520-0442(1997)010<1004:ELIV>2.0.CO;2

[11] K. E. Trenberth. and J. W. Hurrell, "Decadal Atmosphere-Ocean Variations in the Pacifc," Climate Dynamics, Vol. 9, 1994, pp. 303-319.doi:10.1007/BF00204745

[12] W. J. Burroughs, Climate Change a Multidisciplinary
Approach, Cambridge University Press, New York, 2001.

[13] W. J. Burroughs, Weather Cycles Real or Imaginary? Cambridge University Press, New York. 2003:

[14] W. T. Peterson, , R. C. Hooff, C. A. Morgan, K. L. Hunter, E. Casillas, and J. W. Ferguson, 2006. Ocean Conditions and Salmon Survival in the Northern California Current, Web Document.

http://www.nwfsc.noaa.gov/research/divsions/fed/ecosysr ep.pdf

[15] Hátún, H., M.R. Payne, G. Beaugrand, P.C. Reid, A.B. Sandø, H. Drange, B. Hansen, J.A. Jacobsen, D. Bloch, 2009: Large bio-geographical shifts in the north-eastern Atlantic Ocean: From the subpolar gyre, via plankton, to blue whiting and pilot whales, Progress in Oceanography, 80, 149-162. doi:10.1016/j.pocean.2009.03.001

[16] Ebbesmeyer, C.C., Dr.Cayan, D.R. McLain, F.H. Nichols, D.H. Peterson and K.T. Redmond, 1991: 1976 step in the Pacific climate: forty environmental changes between 1968-75 and 1977-1984. In: Proc. $7^{\text {th }}$ Ann. Pacific Climate Workshop, California Dept of Water Resources, Interagency Ecol. Stud. Prog. Report 26.

[17] Overland, J., S. Rodionov, S. Minobe and N. Bond, 2008: North Pacific Regime shifts: Definitions, issues and recent transitions. Progress in Oceanography, 77, 92-102. doi:10.1016/j.pocean.2008.03.016

[18] Overland, J. E., J.M. Adams, H.O. Mofjeld, 2000: Chaos in the North Pacific: spatial modes and temporal irregularity, Progress in Oceanography, 47, 337-354. doi:10.1016/S0079-6611(00)00041-0

[19] Collie, J.S., K. Richardson, J. H. Steele, 2004: Regime shifts: can ecological theory illuminate the mechanisms?, Progress in Oceanography, 60, 281-302. doi:10.1016/j.pocean.2004.02.013

[20] Kim, H-J, and A.J. Miller, 2007. Did the Thermocline Deepen in the California Currentafter the 1976/77 Climate Regime shift?, Journal of Physical Oceanography, 37, 1733-1739. doi:10.1175/JPO3058.1

[21] Aebisher, N. J, Coulson, J. C., \& Colebrook, J. M. (1990). Parallel long-term trendsacross four marine trophic levels and weather, Nature, 347, 753-755. doi:10.1038/347753a0

[22] Schneider, N, and B. D. Cornuelle, 2005: The Forcing Of The Pacific Decadal Oscillation, Journal Of Climate, Vol 18, 4355-4373. doi:10.1175/JCLI3527.1

[23] Mantua, N.J., S.R. Hare, Y. Zhang, J.M. Wallace and R.C. Francis, June 1997: A Pacific Interdecadal Climate Oscillation with Impacts on Salmon Production, Bull. Am. Meteorol. Soc, 78, 1069-1079.

doi:10.1175/1520-0477(1997)078<1069:APICOW>2.0.C $\underline{\mathrm{O} ; 2}$

[24] Minobe, S., \& Mantua, N. (1999). Interdecadal modulation of interannual atmospheric and oceanic variability over the North Pacific. Progress in Oceanography, 43, 163-192. doi:10.1016/S0079-6611(99)00008-7

[25] Chao, Y; M. Ghil and J.C. McWilliams, 2000: Pacific Interdecadal Variability in This Century's Sea Surface Temperatures, Geophys Res Letters, 27, 2261-2264. 


\section{doi:10.1029/1999GL011324}

[26] Hare, S. R., \& Mantua, N. J. (2000). Empirical evidence for North Pacific regime shifts in 1977 and 1989. Progress in Oceanography, 47, 103-145. doi:10.1016/S0079-6611(00)00033-1

[27] McFarlane, G.A., J.A. King, R.J. Beamish, 2000: Have there been recent changes in climate? Ask the fish, Progress in Oceanography 47, 147-169. doi:10.1016/S0079-6611(00)00034-3

[28] McPhaden, M.J., and D. Zhang, 2004: Pacific Ocean Circulation Rebounds, Geophys Res Letters, 31, L18301. doi:10.1029/2004GL020727

[29] McGowan, J.A., M.J. Cayan, L.M. Dorman, 1998: Climate-Ocean Variability and Ecosystem Response in the Northeast Pacific, Science, 281, 210-217. doi:10.1126/science.281.5374.210

[30] Behrenfeld, M.J., R.T. O’Malley, D.A. Siegel, C.R. McClain, J.L. Sarmiento, G.C. Feldman, A.J. Milligan, P.G. Falkowski, R.M. Letelier and E.M. Boss, 7 December 2006: Climate-driven trends in contemporary ocean productivity, Nature, 144, doi:10.1038/nature05317.

[31] Miller, A.J. and N. Schneider, 2000: Interdecadal climate regime dynamics in the North Pacific Ocean: theories, observations and ecosystem impacts. Progress in Oceanography, 47, 355-379. doi:10.1016/S0079-6611(00)00044-6

[32] Minobe and Shoshiro, 1997: A 50-70 year climatic oscillation over the North Pacific and North America. Geophys. Res. Lett., 24(6), 683-686.

[33] [33] Minobe and Shoshiro, 1999: Resonance in bidecadal and pentadecal climate oscillation over the North Pacific: Role in climatic regime shifts. Geophys. Res. Lett., 26(7), 855-858.

[34] Stevens, C., S. Levitus, J. Antonov and T.P. Boyer, 2001: On the Pacific Ocean Regime Shift, Geophys Res Letters, 28, 3721-3724. doi:10.1029/2000GL012813

[35] Minobe and Shoshiro, 2002: Interannual to interdecadal changes in the Bering Sea and concurrent 1998/99 changes over the North Pacific, Progress in Oceanography, 55, 45-64. doi:10.1016/S0079-6611(02)00069-1

[36] McFarlane, G.A, R.J. Beamish, 2001: The re-occurrence of sardines off British Columbia characterises the dynamic nature of regimes, Progress in Oceanography, 49, 151-165. doi:10.1016/S0079-6611(01)00020-9

[37] Beamish, R.J., A.J. Benson, R.M. Sweeting, C.M. Nevelle, 2004: Regimes and the history of the major fisheries off Canada's west coast, Progress in Oceanography, 60, 355-385. doi:10.1016/j.pocean.2004.02.009

[38] Beamish, R.J., R.M. Sweeting and C.M. Nevellie: 2004. Improvement of Juvenile Pacific Salmon Production in a Regional Ecosystem after the 1998 Climatic Regime shift, Transactions of the American Fisheries Society 133: 1163-1175. doi:10.1577/T03-170.1

[39] Beamish,R.J, J. T. Schnute, A. J. Cass, C. M. Neville, and R. M. Sweeting, 2004: The Influence of Climate on the Stock and Recruitment of Pink and Sockeye Salmon from the Fraser River, British Columbia, Canada, Transactions of the American Fisheries Society 133:1396-1412. doi:10.1577/T03-221.1

[40] Alheit, J., and M. Niquen, 2004: Regime shifts in the Humboldt Current ecosystem, Progress in Oceanography, 60, 201-222. doi:10.1016/j.pocean.2004.02.006

[41] Bolt, Jennifer (ed), 2005: Fisheries and the Environment: Ecosystem Indicators of the North Pacific and Their Implications for the North Pacific and Their Implications for Stock Assessment, Proceedings of the First Annual Meeting of the National Marine Fisheries Service's Ecological Indicators Research Program, Alaskan Fisheries Service Center (AFSC) Processed Report 2005-04, pgs 103.

[42] Taguchi, B., S-P Xie, H. Mitsudera, A. Kubokawa, 2005: Response of the Kuroshio Extension to Rossby Waves Associated with the 1970s Climate Regime Shift in a High-Resolution Ocean Model, Journal of Climate, 18, 2979-2995. doi:10.1175/JCLI3449.1

[43] Beaugrand, G., 2004: The North Sea regime shift: evidence, causes, mechanisms and consequences, Progress in Oceanography 60, 245-262. doi:10.1016/j.pocean.2004.02.018

[44] Brodeur R.D., M. B. Decker, L. Ciannelli, J. E. Purcell, N. A. Bond, P. J. Stabeno, E. Acuna, G. L. Hunt Jr., 2008: Rise and fall of jellyfish in the eastern Bering Sea in relation to climate regime shifts, Progress in Oceanography 77, 103-111. doi:10.1016/j.pocean.2008.03.017

[45] Chiba, S., M. N. Aita, K. Tadokoro, T. Saino, H. Sugisaki, K. Nakata, 2008: From climate regime shifts to lower-trophic level phenology: Synthesis of recent progress in retrospective studies of the western North Pacific, Progress in Oceanography, 77, 112-126. doi:10.1016/j.pocean.2008.03.004

[46] Conners M.E., A.B. Hollowed, E. Brown, 2002: Retrospective analysis of Bering Sea bottom trawl surveys: regime shift and ecosystem reorganization, Progress in Oceanography, 55, 209-222. doi:10.1016/S0079-6611(02)00079-4

[47] Drinkwater, K.F., 2006: The regime shift of the 1920s and 1930s in the North Atlantic, Progress in Oceanography, 68, 134-151.

[48] Sugimoto, T., S. Kimura, K. Tadokoro, 2001: Impact of El Nino events and climate regime shift on living resources in the western North Pacific, Progress in Oceanography 49, 113-127. doi:10.1016/S0079-6611(01)00018-0

[49] Hollowed, A.B., S. R. Hare, W. S. Wooster, 2001: Pacific Basin climate variability and patterns of Northeast Pacific marine fish production, Progress in Oceanography, 49, 257-282. doi:10.1016/S0079-6611(01)00026-X

[50] Rebstock, G.A., and Y. S. Kang, 2003: A comparison of three marine ecosystems surrounding the Korean peninsula: Responses to climate change, Progress in Oceanography 59, 357-379. doi:10.1016/j.pocean.2003.10.002

[51] Seo, H., S. Kim, K. Seong, S. Kang, 2006: Variability in scale growth rates of chum salmon (Oncorhynchus keta) in relation to climate changes in the late 1980s, Progress in Oceanography 68, 205-216. 
[52] Suga, T., A. Kato, K. Hanawa, 2000: North Pacific Tropical Water: its climatology and temporal changes associated with the climate regime shift in the 1970s, Progress in Oceanography 47, 223-256. doi:10.1016/S0079-6611(00)00037-9

[53] Yasunaka, S., Hanawa, K., 2002. Regime shifts found in the northern hemisphere SST field. Journal of Meteorological Society of Japan, 80, 119-135. doi:10.2151/jmsj.80.119

[54] Wong, C.S., Liusen Xie, W. W. Hsieh, 2007: Variations in nutrients, carbon and other hydrographic parameters related to the 1976/77 and 1988/89 regime shifts in the sub- arctic Northeast Pacific, Progress in Oceanography, 75, 326-342. doi:10.1016/j.pocean.2007.08.002

[55] Wooster, W.S., C. I. Zhang, 2004: Regime shifts in the North Pacific: early indications of the 1976-1977 event, Progress in Oceanography, 60, 183-200. doi:10.1016/j.pocean.2004.02.005

[56] Zhang, C.I., J. B. Lee b, Y. I. Seo a, S. C. Yoon, S. Kim: 2004: Variations in the abundance of fisheries resources and ecosystem structure in the Japan/East Sea, Progress in Oceanography, 61, 245-265. doi:10.1016/j.pocean.2004.06.009

[57] Baines, P.G. and C.K. Folland, 2007: Evidence for a Rapid Global Climate Shift across the Late 1960s, Journal of Climate, 20, 2721-2744. doi:10.1175/JCLI4177.1

[58] Frauenfeld, O.W., R.E. Davis, M.E. Mann, 2005: A Distinctly Interdecadal Signal of Pacific Ocean-Atmosphere Interaction, Journal of Climate, 18, 1709-1718. doi:10.1175/JCLI3367.1
[59] Miller, A.J., Daniel R. Cayan, Tim P. Barnett, Nicholas E. Graham and Josef M. Oberhuber, 1994: The 1976-77 Climate Shift of the Pacific Ocean, Oceanography, 7, No. $1,21-26$

[60] Wu, L., D. E. Lee and Z. Liu, 2005: The 1976/77 North Pacific Climate Regime Shift: The Role of Subtropical Ocean Adjustment and Coupled Ocean-Atmosphere Feedbacks, Journal of Climate, 18, 5125-5140. doi:10.1175/JCLI3583.1

[61] Ruggerone, G.T., J.L. Nielsen, J. Bumgarner, 2007: Linkages between Alaskan sockeye salmon abundance, growth at sea, and climate, 1955-2002, Deep-Sea Research II, 54, 2776-2793.

[62] Ladd, C. and LuAnne Thompson, 2002: Decadal Variability of North Pacific Central Mode Water, Journal of Physical Oceanography, 32, 2870-2881. doi:10.1175/1520-0485(2002)032<2870:DVONPC $>2.0$. $\underline{\mathrm{CO} ; 2}$

[63] Wilderbuer, T.K., A.B. Hollowed, W.J. Ingraham, Jr., P.D. Spencer, M.E. Conners, N.A. Bond, G.E. Walters, 2002: Flatfish recruitment response to decadal climatic variability and ocean conditions in the eastern Bering Sea, Progress in Oceanography, 55, 235-247. doi:10.1016/S0079-6611(02)00081-2

[64] Tian, Y., H. Kidokoro, T. Watanabe, 2006: Long-term changes in the fish community structure from the Tsushima warm current region of the Japan/East Sea with an emphasis on the impacts of fishing and climate regime shift over the last four decades, Progress in Oceanography, 68, 217-237. 